\title{
Catalysis of the Aza-Diels-Alder Reaction by Hydrogen and Halogen Bonds
}

\author{
Vincent de Paul N. Nziko and Steve Scheiner* \\ Department of Chemistry and Biochemistry \\ Utah State University \\ Logan, UT 84322-0300
}

\begin{abstract}
The combination of $\mathrm{H}_{2} \mathrm{C}=\mathrm{NH}$ and cis-1,3-butadiene to form a six-membered ring was examined by quantum calculations. The energy barrier for this reaction is substantially lowered by the introduction of an imidazolium catalyst with either a $\mathrm{H}$ or halogen $(\mathrm{X})$ atom in the 2-position, which acts via a $\mathrm{H}$ or halogen bond to the $\mathrm{N}$ atom of the imine, respectively. $\mathrm{X}=\mathrm{I}$ has the largest effect, and $\mathrm{Cl}$ the smallest; $\mathrm{Br}$ and $\mathrm{H}$ are roughly equivalent. The catalyst retards the formation of the incipient $\mathrm{N}-\mathrm{C}$ bond from imine to diene while simultaneously accelerating the C-C bond formation. The energy of the $\pi^{*} \mathrm{LUMO}$ of the imine is lowered by the catalyst, which thereby enhances charge transfer from the diene to the imine. Assessment of free energies suggests catalytic rate acceleration by as much as four to six orders of magnitude.

*steve.scheiner@usu.edu
\end{abstract}

Keywords: NBO; AIM; M06-2X; SAPT; activation strain 


\section{INTRODUCTION}

Organocatalysts have found widespread use in the synthesis of natural products and pharmaceutically relevant molecules from readily available small organic precursor molecules. This method of synthesis is cost effective, operationally simple, and easy ${ }^{1-2}$ to handle. Those organocatalysts that interact with their substrate through a hydrogen bond (HB) have been especially widely developed and used. For example the Jacobsen group ${ }^{3}$ has successfully used chiral bifunctional urea to catalyze the Povarov reaction that involves an imine and an enamine. BINOL is another widely used organocatalyst which acts as both proton donor and acceptor ${ }^{4-7}$ through the intermediate of a HB that has been applied to a variety of reactions including hydride transfer.

There has been growing interest in other sorts of organocatalysts that proceed via noncovalent interactions other than H-bonding. Organic molecules that have the potential to form halogen bonds (XBs) have been a recent source of exploration due to the high linearity and strength of these bonds, comparable and sometimes stronger than a H-bond ${ }^{8-11}$. An important step in applications of the use of XBs in catalysis occurred in 2008 when Bolm et al ${ }^{12}$ demonstrated that fluorinated alkyl halides could catalyze the reduction of substituted quinolines by Hantzsch esters. Various other applications of XB activation followed shortly thereafter ${ }^{13-16}$.

The Diels-Alder reaction has proven over the years to be an effective synthetic strategy for building stereochemically well-defined unsaturated 6-membered rings. The first organocatalyst applied to the DielsAlder reaction was developed by MacMillan and coworkers ${ }^{17}$ in 2000 . This catalyst is believed to work through the formation of a HB and proceeds by a LUMO-lowering activation mechanism. The Diels-Alder

reaction has continued its development over the years and a number of additional catalysts ${ }^{18-20}$ have found application, especially Lewis acids like $\mathrm{AlCl}_{3}$.

The Aza Diels-Alder reaction described in Scheme 1 offers an alternative route for one-step synthesis of functionalized nitrogen-containing heterocyclic rings from readily available imines, coupled with diene components. The regioselectivity, diastereoselectivity, and enantioselectivity of the resulting heterocyclic rings are easily controlled ${ }^{21}$ via this procedure. Just as in the standard Diels-Alder reaction, chiral Lewis acids play an important catalytic role in the aza Diels-Alder reaction. Unfortunately, most Lewis acids end up trapped by the basic nitrogen atoms, either of the starting imine or the final heterocyclic product, thereby hindering the catalytic activity ${ }^{22}$ of these Lewis acids. In other to overcome this drawback, a new generation of catalyst would be very useful. 


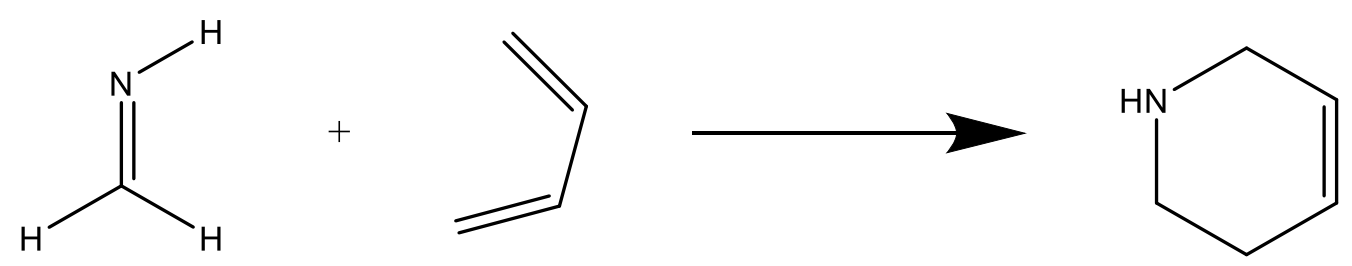

Scheme 1. Aza Diels-Alder Reaction

Following up on the Huber group's finding ${ }^{23}$ that a bis(2-iodoimidazolium) salt could catalyze a DielsAlder reaction, Takeda and co-workers considered ${ }^{24}$ a range of related X-bonding agents in connection with the slightly different aza-Diels-Alder reaction. After noting that a reaction of this sort would not occur in the presence of perfluoroiodobenzene, they found success with a set of more powerful X-bonding 2halogenoimidazolium salts. Their comparison of closely related catalysts suggested that the reaction rate ought to match the expected order of $\mathrm{XB}$ strength; viz. I $>\mathrm{Br}>\mathrm{Cl}$, but left certain other issues incompletely resolved, and they suggested further studies of the details of the reaction mechanism. For example, they were unable to extract any information concerning the transition states of these reactions, nor their energies.

The present work attempts to provide detailed information about this reaction, and specifically about the involvement of any XBs in its catalysis. Quantum calculations are applied in order to take advantage of their ability to elucidate fine details of the structure and energy of transient species such as the transition state, as well as any intermediates in the course of the reaction. These methods are also amenable to analysis of the electronic structure of these species, providing information such as the amount of charge transfer or the energies of frontier molecular orbitals. In this manner, these methods allow one to focus on the mechanism by which a XB is capable of catalyzing the reaction. So as to maximize contact with experimental information, this work focuses on the aza-Diels-Alder reaction studied recently by Takeda et $\mathrm{al}^{24}$. As such we report here the first computational work pertaining to the use of an organocatalyst to catalyze the Diels-Alder reaction via XB formation. The direct influence of the strength of the XB is studied by a comparison of I with $\mathrm{Br}$ and $\mathrm{Cl}$ as the halogen atom on the catalyst. In order to extract further information about the influence of a XB, we also consider an analogous catalyst which replaces the halogen by $\mathrm{H}$, i.e. comparison of $\mathrm{XB}$ with $\mathrm{HB}$.

\section{COMPUTATIONAL METHODS}

All computations were carried out with Gaussian 09, Rev D.01 and B.01 ${ }^{25}$. Geometry optimization and frequency calculations were performed using the M06-2X density functional ${ }^{26}$ with the aug-cc-pVDZ basis set, and ECP aug-cc-PVDZ for I to account for relativistic effects. The performance of this 
computationally affordable level of theory has been shown to be suitable for the geometric, electronic and energetic features of the Diels-Alder (DA) reaction ${ }^{27-29}$. Additional calculations were carried out at the MP2 level, as detailed below. The stationary points were characterized by frequency calculations, and all transition states were confirmed to have a single imaginary frequency corresponding to the formation of the expected bonds. The NBO method ${ }^{30-32}$ was used to measure the charge transfer involved in this reaction. The interaction energy was dissected using symmetry-adapted perturbation theory (SAPT) methods ${ }^{33-35}$.

So as to examine the essence of the reaction, free of complicating substituent effects, model reactants and catalysts were studied here. $\mathrm{H}_{2} \mathrm{C}=\mathrm{NH}$ and cis-1,3-butadiene were chosen as reactants that ultimately coalesce to form a six-membered ring. The imidazolium catalysts placed an $\mathrm{X}$ atom $(\mathrm{X}=\mathrm{I}, \mathrm{Br}, \mathrm{Cl})$ in the 2position, along with methyl groups on the two $\mathrm{N}$ atoms so as to closely mimic the cations examined earlier 24. The halogen atom was replaced by $\mathrm{H}$ so as to compare the results of H-bonding on this reaction.

\section{RESULTS}

Fig 1 outlines the steps in the reaction of interest, and the definition of the various relevant energy terms. The reaction begins with all three units: diene, imine, and catalyst separate and distinct. The first step refers to the binding of the catalyst to the imine, which stabilizes the system by an amount $E_{1}$. The imine-catalyst pair then interacts with the diene substrate forming an encounter complex diene $\cdot \operatorname{Im} \cdot \cdot \mathrm{cat}$, further lowering the total energy by $\mathrm{E}_{2}$. The reaction then proceeds through a transition state TS which requires energy $\mathrm{E}_{3}$ from the encounter complex. The reaction next proceeds to form the heterocyclic sixmembered ring, still bound to the catalyst, product $\cdots$ cat, liberating $\mathrm{E}_{6}$ units of energy. The final step, requiring $\mathrm{E}_{7}$, separates the product from the regenerated catalyst which can now go on to reinitiate the reaction with a new substrate. Overall, starting from the beginning with separate diene, imine, and catalyst, the total reaction energy $E_{r e a c}$, can be expressed in terms of the other quantities, e.g. $E_{r e a c}=E_{1}+E_{2}+E_{3}+E_{6}$ $+\mathrm{E}_{7}$. The quantity $\mathrm{E}_{5}$ represents the energy of the TS relative to the starting reactants, which can be considered the activation energy of the entire reaction. E5 can also be expressed as the sum of other terms: $\mathrm{E}_{5}=\mathrm{E}_{1}+\mathrm{E}_{2}+\mathrm{E}_{3}$. 


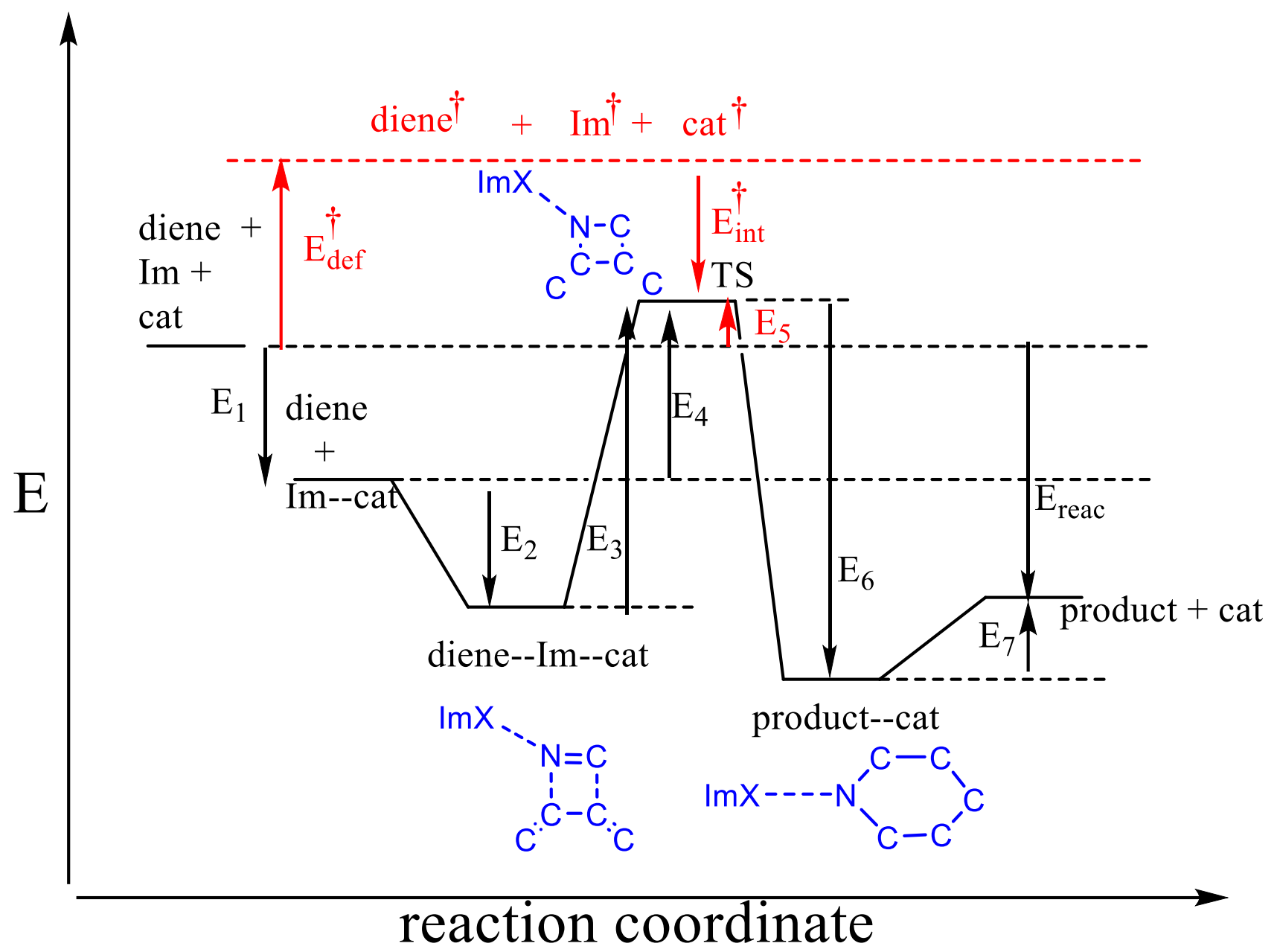

Fig. 1. Energy diagram of aza-Diels-Alder reaction of diene with imine (Im) and catalyst (cat)

\section{Geometries}

Some of the pertinent geometries are exhibited in Fig 2. The upper set of structures corresponds to the uncatalyzed aza-Diels-Alder reaction in which the imine first forms an encounter complex with the diene. After overcoming the transition state, the six-membered heterocyclic ring is formed as product. Immediately below this set of structures is the same reaction in the presence of a H-bonding imidazolium catalyst, and the I-substituted analogues are shown directly below. The encounter complexes on the left show how the imine approaches the diene from above with its $\mathrm{C}$ and $\mathrm{N}$ atoms directly above the two terminal $\mathrm{CH}_{2}$ groups of the diene. At the same time, the $\mathrm{H} / \mathrm{I}$ atoms of the catalyst engage in a $\mathrm{H} / \mathrm{halogen}$ bond with the imine $\mathrm{N}$ atom. The transition states follow the natural course of a closer approach of the imine to the diene, as the $\mathrm{C}-\mathrm{C}$ and $\mathrm{C}-\mathrm{N}$ bonds between them begin to form, still retaining the $\mathrm{H} / \mathrm{halogen}$ bonds to the catalyst. These same noncovalent bonds are present in the product" ${ }^{-c a t a l y s t}$ complex 
following the full formation of the $\mathrm{C}-\mathrm{C}$ and $\mathrm{C}-\mathrm{N}$ bonds which characterize the six-membered heterocyclic ring. All that remains is the disengagement of the catalyst from this product.

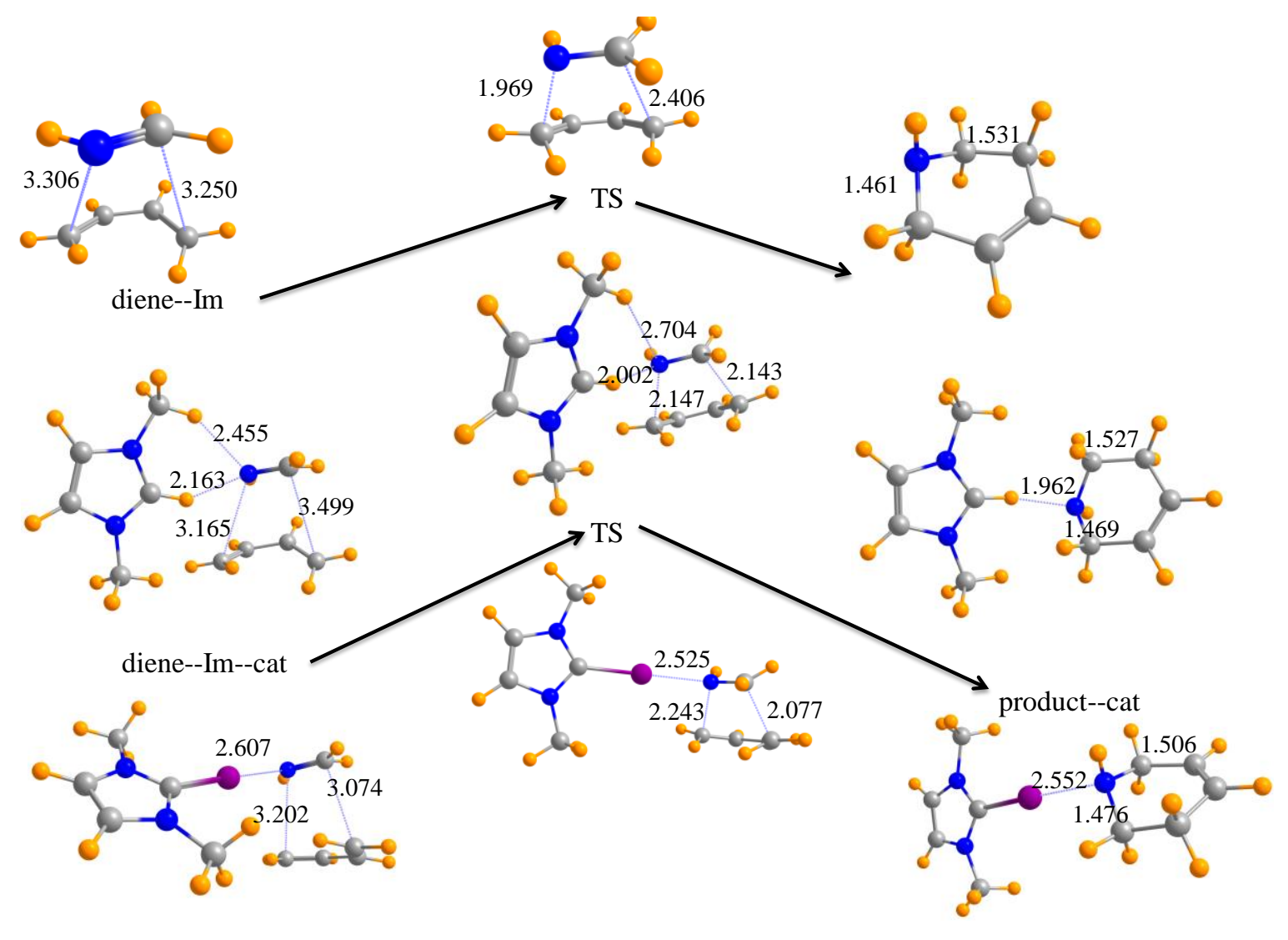

Fig. 2. Encounter complex, transition state (TS) and product with no catalyst (top), H-bonding catalyst (middle), and I-bonding catalyst (bottom). Distances in $\AA$.

Some of the geometrical parameters in Fig 2 suggest the influence of the catalyst. First considering the initial encounter complex, the $\mathrm{R}(\mathrm{N} \cdot \mathrm{C})$ and $\mathrm{R}(\mathrm{C} \cdot \mathrm{C})$ distances are 3.306 and $3.250 \AA$, respectively in the uncatalyzed structure. The $\mathrm{H}$ bond from the imine $\mathrm{N}$ to the H-bonding catalyst is rather short, $2.163 \AA$, suggesting a good deal of binding strength. This HB "tips" the imine, so that the R(N*C) distance to the diene is shortened and the $\mathrm{R}(\mathrm{C} \cdot \mathrm{C})$ counterpart is lengthened. The I-substituted catalyst on the other hand, shortens both of these bonds, although the contraction is a bit greater for $\mathrm{R}(\mathrm{C} \cdot \mathrm{C})$.

Turning next to the transition states, $\mathrm{R}(\mathrm{N} \cdot \mathrm{C})=1.969 \AA$ and $\mathrm{R}(\mathrm{C} \cdot \mathrm{C})=2.406 \AA$ in the uncatalyzed process. The former is lengthened and the latter shortened with the HB catalyst, the reverse of the effect of this catalyst upon the encounter complex. The I-substituted catalyst also lengthens $R(C \cdot \cdot N)$ and contracts $\mathrm{R}(\mathrm{C} \cdot \mathrm{C})$, and to a greater extent than does the HB catalyst. One might say that the presence of either 
catalyst alters the synchronicity of the formation of the two incipient bonds, delaying the formation of C-N while hastening the formation of $\mathrm{C}-\mathrm{C}$. Considering the $\mathrm{H}$-bonding catalyst, $\mathrm{R}(\mathrm{H} \cdot \mathrm{N})$ to the imine is equal to $2.163 \AA$ in the encounter complex, and becomes shorter, and presumably stronger as the reaction proceeds, culminating in a HB length of less than $2 \AA$ in the product. The $\mathrm{I} \cdot \mathrm{N}$ halogen bond is shortest in the transition state.

These interatomic distances are displayed in Table 1 along with the equivalent data for the $\mathrm{Cl}$ and $\mathrm{Br}$ substituted imidazolium catalysts. There are certain trends apparent in a comparison of the three halogen atoms. Most notable is the shortening of the $\mathrm{R}(\mathrm{N} \cdot \mathrm{X})$ halogen bond distance as one proceeds from $\mathrm{Cl}$ to $\mathrm{Br}$ to I in all structures: encounter complex, TS, and product. This contraction is clear evidence of strengthening interaction since the halogen radius is increasing in this progression. This halogen bond becomes shorter as the reaction proceeds in most cases, although this is not a strong trend.

Table 1. Interatomic distances $(\AA)$

\begin{tabular}{|l|l|l|l|l|l|}
\hline & none & $\mathrm{H}$ & $\mathrm{Cl}$ & $\mathrm{Br}$ & $\mathrm{I}$ \\
\hline \multicolumn{6}{|c|}{ encounter complex } \\
\hline $\mathrm{R}(\mathrm{N} \cdot \mathrm{C})$ & 3.306 & 3.165 & 3.237 & 3.218 & 3.202 \\
\hline $\mathrm{R}(\mathrm{C} \cdot \mathrm{C})$ & 3.250 & 3.499 & 3.290 & 3.472 & 3.074 \\
\hline $\mathrm{R}(\mathrm{N} \cdot \cdot \mathrm{H} / \mathrm{X})$ & - & 2.163 & 2.780 & 2.738 & 2.607 \\
\hline \multicolumn{7}{|c|}{$\mathrm{TS}$} \\
\hline $\mathrm{R}(\mathrm{N} \cdot \mathrm{C})$ & 1.969 & 2.147 & 2.205 & 2.146 & 2.243 \\
\hline $\mathrm{R}(\mathrm{C} \cdot \mathrm{C})$ & 2.406 & 2.143 & 2.098 & 2.160 & 2.077 \\
\hline $\mathrm{R}(\mathrm{N} \cdot \mathrm{H} / \mathrm{X})$ & - & 2.002 & 2.737 & 2.644 & 2.525 \\
\hline \multicolumn{7}{|c|}{ product } \\
\hline $\mathrm{R}(\mathrm{N} \cdot \mathrm{C})$ & 1.461 & 1.469 & 1.468 & 1.469 & 1.474 \\
\hline $\mathrm{R}(\mathrm{C} \cdot \mathrm{C})$ & 1.531 & 1.527 & 1.529 & 1.528 & 1.527 \\
\hline $\mathrm{R}(\mathrm{N} \cdot \cdot \mathrm{H} / \mathrm{X})$ & - & 1.962 & 2.731 & 2.623 & 2.552 \\
\hline
\end{tabular}

As the reaction proceeds through transition state and product, the $\mathrm{R}(\mathrm{N} \cdot \mathrm{C})$ and $\mathrm{R}(\mathrm{C} \cdot \mathrm{C})$ bonds of course become shorter. But the presence of a catalyst affects the timing of the reaction. Beginning with the encounter complex, in comparison to the uncatalyzed reaction in the first column of Table 1 , the $R(N \cdot C)$ bond is shorter, and the $\mathrm{R}(\mathrm{C} \cdot \mathrm{C})$ bond longer (with the exception of the I substituent). Within the transition state, the catalyst has the opposite effect, lengthening $R(N \cdot \cdot C)$ and contracting $R(C \cdot \cdot C)$. In other words, the catalyst appears to delay the formation of the former bond while hastening the latter. This trend is not very sensitive to the nature of the catalyst, although I shows the greatest effect in this regard. Because of differential effects by each catalyst, it may be noted that the $\mathrm{N} \cdot \mathrm{C}$ bond is longer than $\mathrm{C} \cdot \mathrm{C}$ for the transition states of $\mathrm{Cl}$ and $\mathrm{I}$, but roughly equal for $\mathrm{H}$ and $\mathrm{Br}$. 
A perhaps more quantitative way of discussing the progress of the reaction is as follows. The $\mathrm{N} \cdot \mathrm{C}$ distance in the encounter complex (of the uncatalyzed process) is $3.306 \AA$. This same distance is $1.461 \AA$ in the product, so there is a total change of $1.845 \AA$ occurring upon reaction. The $\mathrm{N} \cdot{ }^{*} \mathrm{C}$ distance in the TS is 1.969 , which is $1.337 \AA$ smaller than that in the encounter complex. The percentage change of this distance in the TS, relative to the total change required for full reaction is thus $1.337 / 1.845=0.725$. This same fractional change in the TS relative to the final product in the catalyzed reactions are smaller, in the range between 0.56 and 0.61 , confirming more quantitatively the delay in the formation of the $\mathrm{N}-\mathrm{C}$ bond. Application of the analogous formula for the $\mathrm{C}-\mathrm{C}$ bond leads to a fractional formation in the TS of 0.49 in the uncatalyzed reaction, and 0.64-0.69 when a catalyst is present, reaffirming the acceleration of the formation of this bond by the catalyst.

In addition to monitoring the progress of the incipient bonds between the imine and diene, one can also consider the bond length changes within the diene itself. The three $\mathrm{R}(\mathrm{CC})$ bonds in the optimized diene are $1.337,1.476$, and $1.337 \AA$, respectively, corresponding to the alternating double-single-double nature of these bonds. After the reaction is complete, these three bond lengths are 1.507, 1.336 and $1.509 \AA$, respectively (where the last one corresponds to $\mathrm{C}_{3} \mathrm{C}_{4}$, adjacent to the $\mathrm{N}$ ). As anticipated by the transitions between single and double bond character in the aza-Diels-Alder reaction, the central bond shortens (by $0.140 \AA$ ) and the two terminal bonds elongate (by $0.17 \AA$ ).

The bond lengths in the transition state serve as a gauge of the progress of each bond toward its eventual bond length in the product. Considering the uncatalyzed reaction first, the three $\mathrm{C}-\mathrm{C}$ bond lengths in the diene are equal to $1.373,1.413$, and 1.390 , which respectively represent 21,45 , and $30 \%$ of their full changes upon reaching the product. The presence of a catalyst alters these percentage changes to 25,48 and $25 \%$, respectively. In other words, the catalyst speeds up the progress of the first two bonds toward their eventual length, while simultaneously retarding the progress of the third bond (the one adjacent to the $\mathrm{N}$ atom in the final product). This effect is largely insensitive to the particular nature of the catalyst, with only small differences from one catalyst to the other.

\section{Energetics}

The computed values of the various energies defined in Fig 1 are reported in Table 2, first for the uncatalyzed reaction in the first row, encompassing only the imine and diene. The imidazole-catalyzed quantities are listed in the ensuing four rows, headed by the identity of the atom on the imidazole catalyst, whether $\mathrm{H}$ or one of the halogens. Comparison of these quantities provides insight into the activity of each catalyst. The first column corresponds to the strength of the interaction between the imidazole and the imine. The H-bonding pair is bound by $12.9 \mathrm{kcal} / \mathrm{mol}$. Replacing $\mathrm{H}$ by $\mathrm{Cl}$ weakens this binding while I- 
substitution strengthens the interaction by some $6 \mathrm{kcal} / \mathrm{mol}$; Br has a small weakening effect. The binding of this catalyst-imine pair to the diene, $\mathrm{E}_{2}$, is considerably weaker. Without a catalyst at all, the diene and imine are bound by $3.9 \mathrm{kcal} / \mathrm{mol}$, whereas the catalyst-imine pair binds slightly more strongly, by 4-6 $\mathrm{kcal} / \mathrm{mol}$. This cooperative effect can be attributed to the fact that the imine $\mathrm{N}$ atom serves as electron donor to the catalyst (whether $\mathrm{HB}$ or $\mathrm{XB}$ ) while accepting charge from the $\pi$-system of the diene.

Table 2. Energetics ( $\mathrm{kcal} / \mathrm{mol})$ of aza-Diels-Alder reaction with various substitutions on catalyst

\begin{tabular}{|l|l|l|l|l|l|l|l|l|l|l|}
\hline & $\mathrm{E}_{1}$ & $\mathrm{E}_{2}$ & $\mathrm{E}_{3}$ & $\mathrm{E}_{4}$ & $\mathrm{E}_{5}$ & $\mathrm{E}_{6}$ & $\mathrm{E}_{7}$ & $\mathrm{E}_{\text {react }}$ & $\mathrm{E}_{\text {def }}^{\dagger}$ & $\mathrm{E}_{\text {int }}^{\dagger}$ \\
\hline none & 0 & -3.91 & 17.69 & 13.78 & 13.78 & -57.07 & 0 & -43.30 & 17.30 & -3.56 \\
\hline $\mathrm{H}$ & -12.86 & -5.57 & 18.62 & 13.05 & 0.18 & -57.45 & 13.97 & -43.30 & 24.35 & -24.17 \\
\hline $\mathrm{Cl}$ & -9.27 & -4.54 & 18.46 & 13.92 & 4.65 & -58.12 & 10.17 & -43.30 & 22.17 & -17.54 \\
\hline $\mathrm{Br}$ & -11.70 & -5.61 & 18.68 & 13.07 & 1.37 & -58.57 & 13.91 & -43.30 & 23.27 & -21.87 \\
\hline $\mathrm{I}$ & -18.48 & -3.93 & 17.40 & 13.47 & -5.02 & -58.63 & 20.35 & -43.30 & 26.54 & -31.56 \\
\hline
\end{tabular}

Transition to the TS from the fully bound system $\left(\mathrm{E}_{3}\right)$, requires some $17.4-18.7 \mathrm{kcal} / \mathrm{mol}$, and is rather insensitive to the presence of a catalyst or the nature of the substituent. The same can be said of $\mathrm{E}_{4}$, which differs from $\mathrm{E}_{3}$ only by the binding of the diene to the catalyst-imine pair. It might be noted that neither $\mathrm{E}_{3}$ nor $\mathrm{E}_{4}$ show a strong effect from the presence of a catalyst, regardless of its substituent.

The most important quantity in Table 2 is $E_{5}$, which corresponds to the activation energy of the reaction. This term is equal to $13.8 \mathrm{kcal} / \mathrm{mol}$ for the uncatalyzed process, but is much smaller for the various catalysts. In fact, for the I-substituted imidazolium, the transition state is more stable than the separate reactants, leading to a negative value of $E_{5}$. Comparison of the preceding terms in Table 2 leads to insights into how the catalysts reduce the activation energy. The binding energy $\mathrm{E}_{2}$ of the diene is more negative for the catalyzed reaction, but only slightly. The energy needed to transit from the encounter complex to the transition state, $\mathrm{E}_{3}$, is barely affected by the presence of any of the catalysts.

The biggest difference between uncatalyzed and catalyzed reactions resides in the binding of the imine to the catalyst, $\mathrm{E}_{1}$. This quantity varies from a minimum of $9 \mathrm{kcal} / \mathrm{mol}$ for $\mathrm{Cl}$ up to $18.5 \mathrm{kcal} / \mathrm{mol}$ for I; $\mathrm{H}$ lies between with a binding energy of $12.9 \mathrm{kcal} / \mathrm{mol}$. It is this strong binding of the catalyst, whether by $\mathrm{H}-$ bond or halogen bond, that can be taken as primarily responsible for the reduction of $\mathrm{E}_{5}$. Indeed the strength of the I-bond, $18.5 \mathrm{kcal} / \mathrm{mol}$, is large enough that the transition state in which this I-bond is present lies lower in energy than the unassociated reactants where this I-bond is absent. The growing strength of the halogen bond, $\mathrm{Cl}<\mathrm{Br}<\mathrm{I}$, thus matches the reduction of $\mathrm{E}_{5}$, with that of $\mathrm{H}$ intermediate between $\mathrm{Br}$ and I. 
Continuing the reaction beyond the transition state, the ensuing formation of the product $\cdot \cdot$ catalyst complex is quite exothermic, nearly $-60 \mathrm{kcal} / \mathrm{mol}$, and largely independent of the presence of a catalyst. The last step in the catalyzed process is the separation of the catalyst from the product, $\mathrm{E}_{7}$, which amounts to between 10 and $20 \mathrm{kcal} / \mathrm{mol}$. These dissociation energies are slightly larger than $\mathrm{E}_{1}$, representing the binding of the catalyst to the imine, but obey the same trend: Again the I-bonded species requires the most energy to pull apart, and $\mathrm{Cl}$ the least. Following the removal of the catalyst, the final reaction energies are all equally exothermic, $-43.3 \mathrm{kcal} / \mathrm{mol}$.

There are of course several ways of understanding the energetics of catalysis in a reaction such as this. One prescription which has shown itself useful is commonly dubbed the activation strain model ${ }^{27,36-39}$, and is illustrated by the red energies in Fig 1. The transition from the separate reactants to the transition state is envisioned as occurring in two conceptual steps. The first process requires that each of the reactants be deformed into the precise internal geometries they will eventually adopt in the transition state, requiring an amount of energy labeled $\mathrm{E}^{\dagger}$ def. The second step stabilizes the system by an energy $\mathrm{E}^{\dagger}$ int when the properly deformed reactants are allowed to combine together to assemble the transition state. The sum of the latter two terms adds up to the activation energy $\mathrm{E}_{5}$, as indicated in Fig 1.

Both $\mathrm{E}_{\text {def }}^{\dagger}$ and $\mathrm{E}_{\text {int }}^{\dagger}$ are displayed in the last two columns of Table 2. Considering the first row of the table, the deformation energy of the uncatalyzed reaction is $17.3 \mathrm{kcal} / \mathrm{mol}$, which is barely compensated by the interaction energy of only $3.6 \mathrm{kcal} / \mathrm{mol}$, leaving a barrier of $14 \mathrm{kcal} / \mathrm{mol}$. The deformation energies of the catalyzed reactions are larger, $22-27 \mathrm{kcal} / \mathrm{mol}$. But the interaction energies are far more stabilizing than in the uncatalyzed case, between 18 and $32 \mathrm{kcal} / \mathrm{mol}$. In the I case, for example, the interaction energy of $32 \mathrm{kcal} / \mathrm{mol}$ actually exceeds the deformation energy, which leads to the negative activation energy. One may thus conclude that the reduction in $\mathrm{E}_{5}$ arising from the presence of the catalysts can be attributed to the high interaction energies that result from bringing the pre-deformed species together in order to assemble the transition state. If one considers either $\mathrm{E}_{1}$ or $\mathrm{E}_{7}$ as a measure of the binding energy of the $\mathrm{H} / \mathrm{X}$ bond between the catalyst and the imine $\mathrm{N}$ atom, then this noncovalent bond can be thought of as responsible for roughly half of the total $\mathrm{E}^{\dagger}{ }_{\text {int. }}$.

Fig 3 illustrates the activation strain model visually, wherein the blue downward arrows represent $\mathrm{E}_{\text {int }}^{\dagger}$ and the final activation energies $\mathrm{E}_{5}$ are shown in red. The deformation energy on the left is broken down into the strain of each of the subunits. The deformation energy of the catalyst in brown is very small, less than $2 \mathrm{kcal} / \mathrm{mol}$ in all cases. The strain undergone by the diene (black) is the largest of the three, and is 2 or $3 \mathrm{kcal} / \mathrm{mol}$ larger in the four catalyzed cases than in the uncatalyzed reaction. The (green) deformation energy of the imine is smaller, less than $9 \mathrm{kcal} / \mathrm{mol}$, and is also larger in the catalyzed situations. The 
greatest imine strain $(8.7 \mathrm{kcal} / \mathrm{mol})$ occurs for the I-catalyst, as compared to about $6.7 \mathrm{kcal} / \mathrm{mol}$ for the other three catalyst processes. But as indicated above, the largest single factor that differentiates one reaction from the next is the interaction energy, characterized by the blue downward arrows of very different length, which is the primary factor in the effect of catalyst upon activation energy.

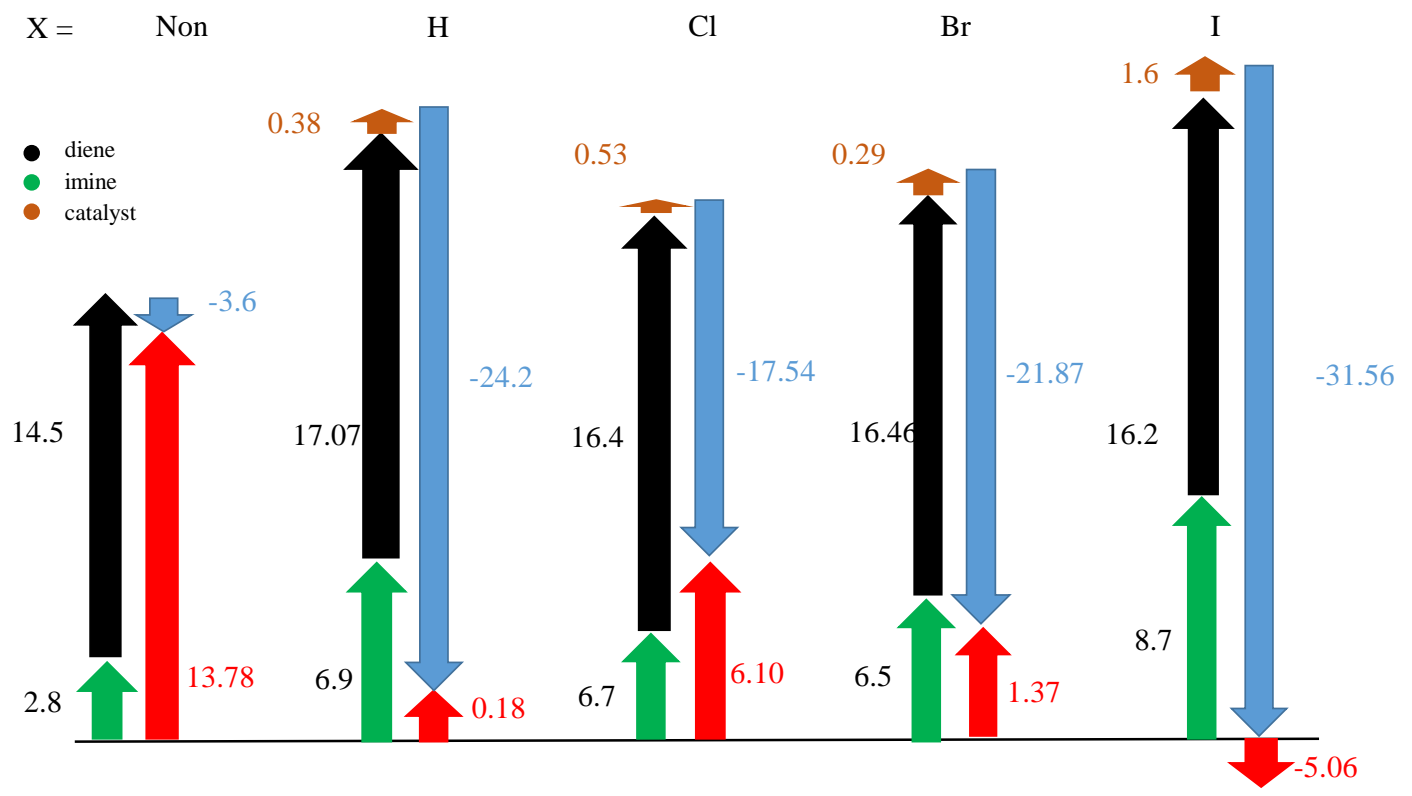

Fig. 3. Deformation energies (kcal/mol) of imine (green) and diene (black), catalyst (brown), and interaction energy (blue) of reaction with indicated catalyst. Total activation energy in red.

\section{Electronic Structure Analysis}

It is clear that one important effect of the catalyst is its formation of a H/X bond with the imine $\mathrm{N}$ atom. One can also inquire as to the effect of each catalyst upon other factors that influence the stability of the transition state. In particular, how might the catalyst affect the interactions between the imine and the diene within the transition state?

The energetic manifestation of the charge transfer taking place between the imine and diene within the TS can be assessed via the NBO formalism which evaluates the second order perturbation energy for the transfer between any given pair of orbitals. Table 3 displays these values of $E(2)$ which shows first that there is a good deal of transfer in both directions. The transfers involve the $\pi$-systems of the two molecules. Charge is shifted from the occupied $\pi$-orbitals of each molecule to the vacant $\pi^{*}$ antibonding orbitals of the other. The diene contains a pair of $\pi$ bonds (and antibonds), and the imine has a single pair involving the $\mathrm{C}-\mathrm{N}$ bond. 
Comparison of the first two rows of Table 3 suggest the transfer from diene to imine is considerably larger than that for the reverse process. The imine $\rightarrow$ diene transfer is relatively insensitive to the presence or absence of a catalyst, or the nature of the latter. The diene $\rightarrow$ imine transfer, however, is rather strongly dependent upon the catalyst. This transfer amounts to $50 \mathrm{kcal} / \mathrm{mol}$ in the non-catalyzed process, but rises to as much as $74 \mathrm{kcal} / \mathrm{mol}$ when a catalyst is present. In fact, the value of this quantity in the first row of Table 3 correlates rather well with reduction in the $\mathrm{E}_{5}$ activation energies in Table 2, with order: uncatalyzed $<\mathrm{Cl}<\mathrm{Br}<\mathrm{H}<\mathrm{I}$. One can thus conclude that one means by which the catalysts help to accelerate the reaction is via the facilitation of charge transfer from diene to imine. This trend is sensible in that the $\mathrm{H} / \mathrm{X}$ bond acts to suck density away from the imine, thereby allowing the latter to act as a better electron acceptor from the diene.

Table 3. NBO values of $\mathrm{E}(2)(\mathrm{kcal} / \mathrm{mol})$ between imine and diene within the TS

\begin{tabular}{|l|r|r|r|r|r|}
\hline & \multicolumn{1}{l|}{ none } & \multicolumn{1}{l|}{ H } & \multicolumn{1}{l|}{ l } & \multicolumn{1}{l|}{ l } & \multicolumn{1}{l|}{} \\
\hline diene $\rightarrow$ imine & 49.99 & 64.94 & 58.57 & 61.85 & 73.81 \\
\hline imine $\rightarrow$ diene & 27.47 & 25.04 & 25.48 & 23.89 & 21.66 \\
\hline$\pi\left(\mathrm{C}_{3} \mathrm{C}_{4}\right)^{\mathrm{a}} \rightarrow \pi^{*}(\mathrm{NC})$ & 31.99 & 19.29 & 22.26 & 18.91 & 12.96 \\
\hline$\pi\left(\mathrm{C}_{1} \mathrm{C}_{2}\right) \rightarrow \pi^{*}(\mathrm{NC})$ & 18.00 & 45.65 & 36.31 & 42.94 & 60.85 \\
\hline$\pi(\mathrm{NC}) \rightarrow \pi^{*}\left(\mathrm{C}_{3} \mathrm{C}_{4}\right)$ & 23.56 & 15.41 & 17.44 & 14.86 & 10.85 \\
\hline$\pi(\mathrm{NC}) \rightarrow \pi^{*}\left(\mathrm{C}_{1} \mathrm{C}_{2}\right)$ & 3.91 & 9.63 & 8.04 & 9.03 & 10.81 \\
\hline
\end{tabular}

${ }^{\mathrm{a}} \mathrm{C}_{3} \mathrm{C}_{4}$ refers to $\mathrm{C}=\mathrm{C}$ bond of diene that is close to imine $\mathrm{N}$, and $\mathrm{C}_{1} \mathrm{C}_{2}$ to the other double bond<smiles>c1ccncc1</smiles>

The last four rows of Table 3 break down the total charge transfer into the individual interorbital quantities. One can see that this is generally an asymmetric process, in that one of the two $\mathrm{C}=\mathrm{C}$ bonds of the diene transfers considerably more charge to the imine than does the other, and this same bond is also a better sink for transfer from the imine. Note that $\mathrm{C}_{3} \mathrm{C}_{4}$, the $\mathrm{C}=\mathrm{C}$ bond that is closest to the imine $\mathrm{N}$, has stronger $\pi\left(\mathrm{C}_{3} \mathrm{C}_{4}\right) \rightarrow \pi^{*}(\mathrm{NC})$ interactions with the imine for the uncatalyzed process in the first column of Table 3. However, this situation reverses, during catalysis and it is the $\mathrm{C}_{1} \mathrm{C}_{2}$ bonding orbital that shows the largest transfer to the imine. This trend is consistent with the intermolecular distances in Table 1. In the uncatalyzed transition state, the imine $\mathrm{N}$ is considerably closer to the diene than is the imine $\mathrm{C}$ atom, which 
would facilitate the greater transfer from the $\mathrm{C}_{3}=\mathrm{C}_{4}$ bond. In the catalyzed processes, on the other hand, this distinction vanishes and in fact it is the imine $\mathrm{C}$ atom that is closer to the diene in a number of cases. This trend is most obvious for the I-catalyst where $\mathrm{R}(\mathrm{C} \cdot \mathrm{C})$ is some $0.2 \AA$ shorter than is $\mathrm{R}(\mathrm{N} \cdot \mathrm{C})$, and the transfer from $\pi\left(\mathrm{C}_{1} \mathrm{C}_{2}\right)$ is nearly 5 times larger than $\mathrm{E}(2)$ from $\pi\left(\mathrm{C}_{3} \mathrm{C}_{4}\right)$.

In addition to the transfer between individual orbitals, it is of interest to consider the transfer between the overall chemical groups participating in the reaction. As may be seen in the first column of Table 4, only 2 me of charge transfer from the diene to the imine in the uncatalyzed encounter complex, and there is even less transfer within the transition state. The presence of a cationic catalyst absorbs a certain amount of charge, as evident by the values of less than unity in the third row of Table 4 . In the encounter a greater share of the positive charge winds up on the imine than on the diene, consistent with the greater proximity of the former. However, this situation changes drastically as the reaction proceeds to the transition state, where the imine becomes negatively charged, despite the influence of the positively charged catalyst. This negative charge arises via transfer from the diene which takes on a fairly large positive charge. This transfer from diene to imine is consistent with the NBO analysis above. The lower section of Table 4 reflects the change in the group charges on going from encounter complex to transition state. Note that the catalyst itself undergoes very little change, but it does act to facilitate the transfer from the diene which becomes more positive and the imine which becomes more negative. With respect to trends, the loss of charge by the diene follows the same $\mathrm{Cl}<\mathrm{Br}<$ I order as do many other quantities here, with the H-catalyst similar to $\mathrm{Br}$.

Table 4. NBO group charges (e)

\begin{tabular}{|l|l|l|l|l|l|}
\hline & non & $\mathrm{H}$ & $\mathrm{Cl}$ & $\mathrm{Br}$ & $\mathrm{I}$ \\
\hline & \multicolumn{5}{|c|}{ encounter complex } \\
\hline imine & -0.002 & 0.027 & 0.014 & 0.043 & 0.097 \\
\hline diene & 0.002 & 0.008 & 0.010 & 0.003 & 0.014 \\
\hline cat & - & 0.965 & 0.976 & 0.953 & 0.888 \\
\hline \multicolumn{7}{|c|}{$\mathrm{TS}$} \\
\hline imine & 0.000 & -0.098 & -0.071 & -0.072 & -0.062 \\
\hline diene & 0.000 & 0.140 & 0.097 & 0.136 & 0.206 \\
\hline cat & - & 0.958 & 0.974 & 0.936 & 0.856 \\
\hline \multicolumn{7}{|c|}{$\Delta \mathrm{q}=\mathrm{q}(\mathrm{TS})-\mathrm{q}($ encounter complex $)$} \\
\hline imine & 0.002 & -0.125 & -0.085 & -0.116 & -0.160 \\
\hline diene & -0.002 & 0.131 & 0.087 & 0.133 & 0.192 \\
\hline cat & - & -0.007 & -0.002 & -0.017 & -0.032 \\
\hline
\end{tabular}


Frontier molecular orbitals offer another lens through which to view this reaction. The primary interaction would be expected between the HOMO of the diene and the LUMO of the imine, both of which are of $\pi$-type. The energy of the HOMO of the diene is -0.3393 au. As indicated in the first entry of Table 5 , the LUMO energy of the imine is +0.0108 au, leading to a gap between them of 0.3501 au. The succeeding entries in the first row of Table 5 indicate that the association of the imine with each catalyst lowers its LUMO energy, by an amount varying between 0.100 au for $\mathrm{Cl}$ up to 0.124 au for I. This lowering would also reduce the HOMO-LUMO gap which would serve to facilitate the electron transfer. In fact, there is a certain degree of correlation between the reduction of this gap and the activation energy E5. Specifically, the LUMO energy reduction follows the same $\mathrm{Cl}<\mathrm{Br}<$ I order as does activation energy drop. On the other hand, the HOMO-LUMO gap for I and H are very nearly the same, although I is a much more effective catalyst, so this correlation is imperfect. The second row of Table 5 lists the comparable information about the more tightly localized NBO LUMO. Their energies are all about 0.05 au higher than the canonical equivalent, and follow a similar $\mathrm{Cl}<\mathrm{Br}<$ I pattern; the gap reduction in the NBO LUMO is a bit larger for I than for $\mathrm{H}$, better reflecting the superior catalytic activity of I.

Table 5. Energy eigenvalues (au) of the $\pi^{*}$ imine LUMO in complex with indicated catalyst

\begin{tabular}{|l|l|l|l|l|l|}
\hline & none & $\mathrm{H}$ & $\mathrm{Cl}$ & $\mathrm{Br}$ & $\mathrm{I}$ \\
\hline canonical LUMO & +0.0108 & -0.1138 & -0.0888 & -0.0961 & -0.1134 \\
\hline NBO LUMO & +0.0666 & -0.0600 & -0.0366 & -0.0447 & -0.0633 \\
\hline
\end{tabular}

With respect to the binding of the catalyst to the imine, so important to the acceleration of the reaction, one can partition this interaction into its component parts. Table 6 displays the results of a SAPT partitioning of the total interaction energy into its three attractive parts. For $\mathrm{H}$ and $\mathrm{Cl}$, the electrostatic component is largest, followed by induction and then dispersion. However, induction overtakes electrostatic attraction as the largest component for the larger halogens $\mathrm{Br}$ and I. Indeed, in the latter case, induction is twice the magnitude of ES. Dispersion makes a smaller, but not negligible contribution in all cases. In terms of trends, the transition from $\mathrm{Cl}$ to $\mathrm{Br}$ results in an increase in all of the components, a trend which accelerates when $\mathrm{Br}$ is replaced by the larger I. The large induction and dispersion energy for I is consistent with its much greater size and polarizability, as well as with prior calculations ${ }^{40}$.

Table 6. Attractive SAPT components $(\mathrm{kcal} / \mathrm{mol})$ of the interaction energy between imine and catalyst, prior to introduction of diene

\begin{tabular}{|l|l|l|l|l|}
\hline & $\mathrm{H}$ & $\mathrm{Cl}$ & $\mathrm{Br}$ & $\mathrm{I}$ \\
\hline ES & -16.22 & -12.47 & -16.98 & -37.41 \\
\hline
\end{tabular}




\begin{tabular}{|l|l|l|l|l|}
\hline IND & -5.98 & -9.56 & -21.77 & -70.82 \\
\hline DISP & -3.86 & -3.50 & -4.67 & -19.68 \\
\hline total & -12.68 & -8.21 & -9.99 & -17.78 \\
\hline
\end{tabular}

\section{Higher Level of Theory and Second Conformation}

It is important to be sure that the patterns and principles arising from the DFT calculations are truly correct, and reflect the real process. For this reason, the calculation of all energies was repeated by the MP2 method, using geometries obtained by M06/2X, all with the same aug-cc-pVDZ basis set. These results are reported in Table S1 and can be compared directly with the DFT data in Table 2. The association energies of each catalyst with the imine, $\mathrm{E}_{1}$, are changed very little by the DFT to MP2 transition. The same may be said of the dissociation of the catalyst from the final product, $\mathrm{E}_{7}$. The MP2 values of the latter quantity are a bit bigger than the DFT quantities but obey the same trend. This similarity of $\mathrm{E}_{1}$ and $\mathrm{E}_{7}$, confirms the two methods are in agreement about the strengths of the various $\mathrm{H}$ or halogen bonds. $\mathrm{E}_{2}$ quantities match well also, again with the proviso that MP2 binding energies are slightly larger, so the two methods are in accord about the binding of the diene. The largest disagreement occurs in the activation energies $\mathrm{E}_{5}$. The transition from M06-2X to MP2 reduces this barrier in the uncatalyzed process by $7 \mathrm{kcal} / \mathrm{mol}$, with slightly larger reductions for the four catalyzed reactions. These reductions are quite uniform from one catalyst to the next, so the M06-2X order of reaction barriers stands up very well against MP2 results. The energy released upon going from transition state to product, $\mathrm{E}_{6}$, is somewhat less negative for MP2, but by a uniform amount of $8-9 \mathrm{kcal} / \mathrm{mol}$, again preserving the DFT patterns. Importantly, the upshot of any differences between the two methods, the final reaction energy $\mathrm{E}_{\text {react }}$, is virtually identical for the two methods, differing by only $1.0 \mathrm{kcal} / \mathrm{mol}$.

With respect to the deformation and interaction energies within the transition state, the application of MP2 to the M06-2X geometries reduces $\mathrm{E}^{\dagger}$ def by a nearly uniform amount of $4 \mathrm{kcal} / \mathrm{mol}$. $\mathrm{E}^{\dagger}$ int becomes more negative, but again by similar amounts from one catalyst type to the other, about $5-7 \mathrm{kcal} / \mathrm{mol}$. In summary, then, the conclusions concerning catalysis derived from the activation strain model are essentially unchanged by the upgrade from M06-2X to MP2.

When the imine approaches the diene, there are two geometric possibilities. As indicated in Fig 2, the $\mathrm{NH}$ proton can adopt a position in toward the two central $\mathrm{C}=\mathrm{C}$ atoms of the diene. In contrast to this endo orientation, this proton could in principle also lie in the opposite or exo direction, away from the $\mathrm{C}=\mathrm{C}$ bond. 
In order to examine this second possibility, parallel calculations were carried out for this exo orientation, and the results are reported in Tables S2-S6.

Comparison with the corresponding endo data in Tables 1-6 reveals only minor changes for the most part. Considering first the encounter complex, Table S2 shows that in most cases, the change from endo to exo elongates the $\mathrm{R}(\mathrm{N} \cdot \mathrm{C})$ distance, but engenders only a small change in the $\mathrm{H} / \mathrm{X}$-bond distance. (The exo encounter complexes differ from the endo cases in that there is a tendency for the diene to associate more closely with the aromatic catalyst than with the imine. This tendency is greatest for the $\mathrm{X}=\mathrm{H}$ and $\mathrm{Cl}$ cases, although the energetic change associated with this relocation is slight.) The $R(N \cdot C)$ stretch persists in the TS albeit to a smaller extent; very little change is observed in the products.

With respect to the energetics in Table S3, the binding of the diene to the imine $\cdot$ catalyst complex, $\mathrm{E}_{2}$, is enhanced a bit in the exo structure particularly for $\mathrm{H}$ and $\mathrm{Cl}$, but the energy jump from the encounter complex to the $\mathrm{TS}, \mathrm{E}_{3}$, is also raised. As a consequence, the important total energy barrier $\mathrm{E}_{5}$ is changed by only small amounts. For example, the energy barrier in the uncatalyzed exo reaction is $3.5 \mathrm{kcal} / \mathrm{mol} \mathrm{higher}$ than for endo, but the changes to the catalyzed energy barriers are even smaller, less than $2 \mathrm{kcal} / \mathrm{mol}$. With respect to the deformation and interaction energies in the TS, these quantities are also changed by little, less than $2 \mathrm{kcal} / \mathrm{mol}$ in most cases.

The switch from endo to exo has some effect on the NBO charge transfers in the transition states, but again these are generally quite small, and confirm the prior finding that a good deal more transfer takes place from the $\pi$ orbitals of the diene to the imine $\pi^{*}$ orbital than in the reverse direction. The same can be said concerning the group charges in Tables 4 and S5. Even less affected by the endo $\rightarrow$ exo change are the orbital energies in Tables 5 and S6, which confirms the prior conclusion that the catalysts reduce the energy barrier in part by a lowering of the energy of the $\pi^{*}$ LUMO of the imine. In summary, the calculations for the exo reaction repeat the findings of the endo geometries in all but the finest quantitative detail.

\section{Free Energies}

Using standard thermochemical formulae it is possible to evaluate the free energy quantities that parallel the electronic energies of Table 2. Tables 7 and 8 display these free energies $(\mathrm{T}=25 \mathrm{C}, \mathrm{p}=1 \mathrm{~atm})$ for each reaction step defined in Fig 1 for the endo and exo geometries, respectively. Inclusion of entropic effects leads to free energies that are generally more positive than $\mathrm{E}$ but the trends observed in the latter quantities remain largely intact. The reactions characterized by $\mathrm{G}_{1}$ and $\mathrm{G}_{2}$ experience the largest positive changes since they involve the association of two separate species into a single entity. But they also exhibit the large halogen-bond energy associated with $\mathrm{I}$, with $\mathrm{G}_{1}$ following the same trend as did $\mathrm{E}_{1}: \mathrm{I}>\mathrm{H}>\mathrm{Br}>$ $\mathrm{Cl}$, and with very similar increments. $\mathrm{G}_{6}$, the drop in energy upon going from the transition state down to 
the product * catalyst complex, is only slightly less negative than $\mathrm{E}_{6}$, both very exothermic quantities of more than $-50 \mathrm{kcal} / \mathrm{mol}$. 
Table 7. Free energies ( $\mathrm{kcal} / \mathrm{mol})$ of aza-Diels-Alder reaction in the endo conformation with various substitutions on catalyst, evaluated at $298 \mathrm{~K}$ and $1 \mathrm{~atm}$.

\begin{tabular}{|l|l|l|l|l|l|l|l|l|}
\hline endo & $\mathrm{G}_{1}$ & $\mathrm{G}_{2}$ & $\mathrm{G}_{3}$ & $\mathrm{G}_{4}$ & $\mathrm{G}_{5}$ & $\mathrm{G}_{6}$ & $\mathrm{G}_{7}$ & $\mathrm{G}_{\text {react }}$ \\
\hline none & 0 & 5.30 & 23.05 & 28.34 & 28.34 & -52.85 & 0 & -24.51 \\
\hline $\mathrm{H}$ & -3.77 & 4.60 & 26.23 & 30.83 & 27.06 & -53.75 & 2.18 & -24.51 \\
\hline $\mathrm{Cl}$ & -0.06 & 8.19 & 23.16 & 31.35 & 31.29 & -56.31 & 0.51 & -24.51 \\
\hline $\mathrm{Br}$ & -1.54 & 4.63 & 24.37 & 29.00 & 27.45 & -55.63 & 3.67 & -24.51 \\
\hline $\mathrm{I}$ & -7.73 & 8.61 & 20.97 & 29.58 & 21.85 & -53.29 & 6.93 & -24.51 \\
\hline
\end{tabular}

Table 8. Free energies $(\mathrm{kcal} / \mathrm{mol})$ of aza-Diels-Alder reaction in the exo conformation with various substitutions on catalyst, evaluated at $298 \mathrm{~K}$ and $1 \mathrm{~atm}$.

\begin{tabular}{|l|l|l|l|l|l|l|l|l|}
\hline exo & $\mathrm{G}_{1}$ & $\mathrm{G}_{2}$ & $\mathrm{G}_{3}$ & $\mathrm{G}_{4}$ & $\mathrm{G}_{5}$ & $\mathrm{G}_{6}$ & $\mathrm{G}_{7}$ & $\mathrm{G}_{\text {react }}$ \\
\hline none & 0 & 5.30 & 26.92 & 32.22 & 32.22 & -56.73 & 0 & -24.51 \\
\hline $\mathrm{H}$ & -3.77 & 2.74 & 27.43 & 30.17 & 26.40 & -53.72 & 2.81 & -24.51 \\
\hline $\mathrm{Cl}$ & -0.06 & 2.83 & 28.91 & 31.74 & 31.68 & -55.05 & -1.14 & -24.51 \\
\hline $\mathrm{Br}$ & -1.54 & 5.88 & 24.45 & 30.33 & 28.79 & -51.89 & -1.41 & -24.51 \\
\hline $\mathrm{I}$ & -7.73 & 8.85 & 22.50 & 31.35 & 23.62 & -51.55 & 3.42 & -24.51 \\
\hline
\end{tabular}

With respect to $\mathrm{G}_{5}$, these quantities are again larger than $\mathrm{E}_{5}$. Inclusion of entropy mutes to a certain extent the dramatic catalytic effects of Table 2, but confirms the catalytic reduction in activation free energy, especially that associated with the I substituent. Indeed, $\mathrm{G}_{5}$ also follows the same $\mathrm{I}>\mathrm{H}>\mathrm{Br}>\mathrm{Cl}$ pattern as does the binding energy $\mathrm{E}_{1}$. The free energies in Tables 7 and 8 may be used to estimate reaction rate accelerations by the catalysts. Assuming an Arrhenius-type relation $\exp \left\{-\left(\mathrm{E}_{\mathrm{cat}}-\mathrm{E}_{\mathrm{uncat}}\right)\right\} / \mathrm{RT}$, the speedup of the reaction by the I-catalyst amounts to $5 \times 10^{4}$ for the endo geometry; this acceleration is even larger, $2 \times 10^{6}$, for the exo structure. The catalytic speedup of the $\mathrm{H}$ and $\mathrm{Br}$ catalysts are smaller, only one order of magnitude for endo, but $2 \times 10^{4}$ and $3 \times 10^{2}$ respectively for exo. In summary, the catalytic reduction of the activation energy is somewhat more prominent for the exo structures, accelerating the rate by as much as 6 orders of magnitude.

In order to be an effective catalyst, the entity must not only reduce the activation energy, but also release its grip upon the product at the conclusion of the reaction. This dissociation corresponds to $\mathrm{E}_{7}$ in Fig 1. While these quantities are fairly large in Table 2, in the $10-20 \mathrm{kcal} / \mathrm{mol} \mathrm{range}$, they are greatly reduced by the impact of entropy. As indicated in Tables 7 and $8, \mathrm{G}_{7}$ is less than $7 \mathrm{kcal} / \mathrm{mol}$, and even slightly exothermic in several instances. In most cases $\mathrm{G}_{7}$ is smaller for the exo structure than for endo, reinforcing the smaller values of $\mathrm{G}_{5}$ for the former geometry. 


\section{SUMMARY AND DISCUSSION}

After first forming a fairly loosely bound encounter complex, the imine and diene go on to a transition state where the incipient C-N and C-C bonds are some 2.0-2.4 $\AA$ in length. This transition state lies 14 $\mathrm{kcal} / \mathrm{mol}$ higher in energy than the separated reactants. The presence of the imidazolium catalyst has a number of effects upon the reaction. Whether $\mathrm{H}, \mathrm{Cl}, \mathrm{Br}$, or I-substituted imidazolium, the catalyst binds tightly to the imine-diene complex. In doing so, it reduces the activation energy from 14 down to less than $5 \mathrm{kcal} / \mathrm{mol}$. The I-substituted imidazolium is most effective in this regard, and $\mathrm{Cl}$ the least; $\mathrm{H}$ and $\mathrm{Br}$ are roughly equivalent. The high effectiveness of I-substitution is thus intimately connected with the strength of halogen bonds including I. Br-bonds are somewhat weaker, and Cl-bonds weaker still, consistent with the trends observed in catalytic rate acceleration. Within the context of the activation strain model, the reduction of the barrier by the catalyst is a result of the high interaction energy connected with the approach of the pre-deformed species as they form the transition state. This stabilization far exceeds any increase in the deformation energy needed by the reactants to achieve their transition state structure.

The catalyst also alters the timing of the reaction, by slowing the formation of the $\mathrm{N}-\mathrm{C}$ bond while hastening $\mathrm{C}-\mathrm{C}$ formation. There is a good deal of $\pi \rightarrow \pi^{*}$ charge transfer in both directions between the imine and diene in the transition state, although the diene $(\pi) \rightarrow \operatorname{imine}\left(\pi^{*}\right)$ transfer is considerably larger. This transfer is amplified by the imidazolium catalyst, and the degree of amplification also follows the energetic trend: $\mathrm{Cl}<\mathrm{H} \sim \mathrm{Br}<\mathrm{I}$. The catalyst also depresses the energy of the electron-accepting $\pi^{*}$ LUMO of the imine, thereby facilitating the charge transfer from the diene.

The catalyst exerts its influence in multifold ways. In the most obvious and direct effect, the H/X bond stabilizes the transition state. The catalyst also facilitates the transfer of charge from the diene to the imine in the transition state. This effect is manifest in both the total charges of the groups themselves, but also in the energies of charge transfer between specific orbitals ( $\pi$ diene $\rightarrow \pi^{*}{ }_{\text {imine}}$ ). The H/X bond to the catalyst facilitates this transfer by lowering the energy of the $\pi^{*}$ imine antibonding orbital, thereby reducing the HOMO-LUMO energy gap.

The effect of the catalysts upon the reaction rate has been considered here via a comparison of the transition state energy with that of the reactants, prior to any association occurring. If one were to consider instead the reaction as beginning after the reactants have already bound to one another, then one might conclude that the catalysts have very little effect upon the activation energy, even raising it by a small amount in some cases. This distinction reconfirms the importance of the binding energy of the catalyst to 
the acceleration of this reaction. The strong catalytic effect of the I-substituted catalyst can thus be directly attributed to the strength of halogen bonds involving this element.

In order to obtain a detailed understanding of the aza-Diels Alder reaction on a molecular level, it is first necessary to study the system without the complicating effects of surrounding molecules that would interact with the reacting system in various ways. The introduction of solvent would cause a multitude of interactions, of a rapidly fluctuating nature, making it extremely difficult to extract the underlying intramolecular effects on the catalysis process. Moreover, each particular solvent would result in differing interactions and effects. It is for this reason that solvation has not been included to this point, but is envisioned as a large scale future endeavor.

\section{ACKNOWLEDGMENTS}

Computer, storage and other resources from the Division of Research Computing in the Office of Research and Graduate Studies at Utah State University are gratefully acknowledged.

\section{SUPPORTING INFORMATION}

Table S1 in the Supporting Information section reports MP2 energetics. The succeeding tables display all corresponding data for the exo configuration. Coordinates of minima and transition states are also listed. 


\section{REFERENCES}

1. Reddi, Y.; Sunoj, R. B. ACS Catalysis 2015, 5, 5794.

2. Maruoka, K.; List, B.; Yamamoto, H.; Gong, L.-Z. Chem. Commun. 2012, 48, 10703.

3. Xu, H.; Zuend, S. J.; Woll, M. G.; Tao, Y.; Jacobsen, E. N. Science 2010, 327, 986.

4. Grayson, M. N.; Pellegrinet, S. C.; Goodman, J. M. J. Am. Chem. Soc. 2012, 134, 2716.

5. Simón, L.; Goodman, J. M. J. Am. Chem. Soc. 2008, 130, 8741.

6. Simón, L.; Paton, R. S. J. Org. Chem. 2015, 80, 2756.

7. Marcelli, T.; Hammar, P.; Himo, F. Chem. Eur. J. 2008, 14, 8562.

8. Bauzá, A.; Mooibroek, T. J.; Frontera, A. ChemPhysChem. 2015, 16, 2496.

9. Politzer, P.; Murray, J. S. A unified view of halogen bonding, hydrogen bonding and other $\sigma$-hole interactions. In Noncovalent Forces, Scheiner, S., Ed. Springer: Dordrecht, Netherlands, 2015; Vol. 19, pp 357.

10. Del Bene, J. E.; Alkorta, I.; Elguero, J. J. Phys. Chem. A 2014, 118, 2360.

11. Scheiner, S. Int. J. Quantum Chem. 2013, 113, 1609.

12. Bruckmann, A.; Pena, M. A.; Bolm, C. Synlett 2008, 2008, 900.

13. Coulembier, O.; Meyer, F.; Dubois, P. Polymer Chemistry 2010, 1, 434.

14. Walter, S. M.; Kniep, F.; Herdtweck, E.; Huber, S. M. Angew. Chem. Int. Ed. 2011, 50, 7187.

15. Kniep, F.; Jungbauer, S. H.; Zhang, Q.; Walter, S. M.; Schindler, S.; Schnapperelle, I.; Herdtweck, E.; Huber, S. M. Angew. Chem. Int. Ed. 2013, 52, 7028.

16. He, W.; Ge, Y.-C.; Tan, C.-H. Org. Lett. 2014, 16, 3244.

17. Ahrendt, K. A.; Borths, C. J.; MacMillan, D. W. C. J. Am. Chem. Soc. 2000, 122, 4243.

18. Berkessel, A.; Vogl, N. Eur. J. Org. Chem. 2006, 2006, 5029.

19. Fringuelli, F.; Girotti, R.; Pizzo, F.; Vaccaro, L. Org. Lett. 2006, 8, 2487.

20. Shirakawa, H.; Sano, H. Synthesis 2014, 46, 1788.

21. Jiang, X.; Wang, R. Chem. Rev. 2013, 113, 5515.

22. Kobayashi, S., Jørgensen, K. A. Cycloaddition Reactions in Organic Synthesis. Wiley-VCH: Weinheim, 2002.

23. Jungbauer, S. H.; Walter, S. M.; Schindler, S.; Rout, L.; Kniep, F.; Huber, S. M. Chem. Commun. 2014, 50, 6281.

24. Takeda, Y.; Hisakuni, D.; Lin, C.-H.; Minakata, S. Org. Lett. 2015, 17, 318.

25. Frisch, M. J.; Trucks, G. W.; Schlegel, H. B.; Scuseria, G. E.; Robb, M. A.; Cheeseman, J. R.; Scalmani, G.; Barone, V.; Mennucci, B.; Petersson, G. A.; Nakatsuji, H.; Caricato, M.; Li, X.; Hratchian, H. P.; Izmaylov, A. F.; Bloino, J.; Zheng, G.; Sonnenberg, J. L.; Hada, M.; Ehara, M.; Toyota, K.; Fukuda, R.; Hasegawa, J.; Ishida, M.; Nakajima, T.; Honda, Y.; Kitao, O.; Nakai, H.; Vreven, T.; Montgomery, J., J. A.; Peralta, J. E.; Ogliaro, F.; Bearpark, M.; Heyd, J. J.; Brothers, E.; Kudin, K. N.; Staroverov, V. N.; Kobayashi, R.; Normand, J.; Raghavachari, K.; Rendell, A.; Burant, J. C.; Iyengar, S. S.; Tomasi, J.; Cossi, M.; Rega, N.; Millam, J. M.; Klene, M.; Knox, J. E.; Cross, J. B.; Bakken, V.; Adamo, C.; Jaramillo, J.; Gomperts, R.; Stratmann, R. E.; Yazyev, O.; Austin, A. J.; Cammi, R.; Pomelli, C.; Ochterski, J. W.; Martin, R. L.; Morokuma, K.; Zakrzewski, V. G.; Voth, G. A.; Salvador, P.; Dannenberg, J. J.; Dapprich, S.; Daniels, A. D.; Farkas, O.; Foresman, J. B.; Ortiz, J. V.; Cioslowski, J.; Fox, D. J. Gaussian 09, Revision B.01; Wallingford, CT, 2009.

26. Zhao, Y.; Truhlar, D. G. Theor. Chem. Acc. 2008, 120, 215.

27. Levandowski, B. J.; Houk, K. N. J. Org. Chem. 2015, 80, 3530.

28. Pieniazek, S. N.; Clemente, F. R.; Houk, K. N. Angew. Chem. Int. Ed. 2008, 47, 7746.

29. Gayatri, G. Ind. J. Chem. 2011, 50A, 1579.

30. Reed, A. E.; Weinhold, F.; Curtiss, L. A.; Pochatko, D. J. J. Chem. Phys. 1986, 84, 5687.

31. Reed, A. E.; Curtiss, L. A.; Weinhold, F. Chem. Rev. 1988, 88, 899.

32. Glendening, E. D.; Landis, C. R.; Weinhold, F. J. Comput. Chem. 2013, 34, 1429. 
33. Szalewicz, K.; Jeziorski, B. Symmetry-adapted perturbation theory of intermolecular interactions. In Molecular Interactions. From Van der Waals to Strongly Bound Complexes, Scheiner, S., Ed. Wiley: New York, 1997; pp 3.

34. Moszynski, R.; Wormer, P. E. S.; Jeziorski, B.; van der Avoird, A. J. Chem. Phys. 1995, 103, 8058.

35. Werner, H.-J.; Knowles, P. J.; Manby, F. R.; Schütz, M.; Celani, P.; Knizia, G.; Korona, T.; Lindh, R.; Mitrushenkov, A.; Rauhut, G.; Adler, T. B.; Amos, R. D.; Bernhardsson, A.; Berning, A.; Cooper, D. L.; Deegan, M. J. O.; Dobbyn, A. J.; Eckert, F.; Goll, E.; Hampel, C.; Hesselmann, A.; Hetzer, G.; Hrenar, T.; Jansen, G.; Köppl, C.; Liu, Y.; Lloyd, A. W.; Mata, R. A.; May, A. J.; McNicholas, S. J.; Meyer, W.; Mura, M. E.; Nicklaß, A.; Palmieri, P.; Pflüger, K.; Pitzer, R.; Reiher, M.; Shiozaki, T.; Stoll, H.; Stone, A. J.; Tarroni, R.; Thorsteinsson, T.; Wang, M.; Wolf, A. MOLPRO, Version 2006; 2010.

36. Wolters, L. P.; Bickelhaupt, F. M. WIRE: Comput. Mol. Sci. 2015, 5, 324.

37. Fernandez, I.; Bickelhaupt, F. M. Chem. Soc. Rev. 2014, 43, 4953.

38. Hayden, A. E.; Houk, K. N. J. Am. Chem. Soc. 2009, 131, 4084.

39. van Zeist, W.-J.; Bickelhaupt, F. M. Org. Biomol. Chem. 2010, 8, 3118.

40. Nziko, V. d. P. N.; Scheiner, S. Phys. Chem. Chem. Phys. 2016183581. 


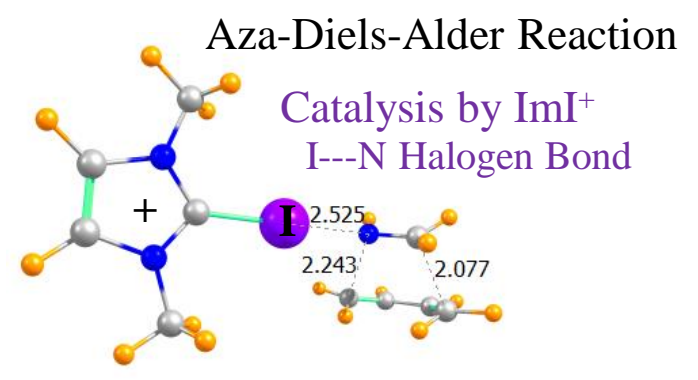

